\title{
LEGAL PROBLEMS OF DIGITALIZATION: THEORETICAL AND LEGAL ASPECTS ${ }^{1}$
}

\author{
Yana V. Gaivoronskaya \\ Far Eastern Federal University, Vladivostok, Russian Federation \\ Olga I. Miroshnichenko \\ Far Eastern Federal University, Vladivostok, Russian Federation
}

Introduction: digitalization is an interdisciplinary problem, but the degree of its mediation by specialists in different fields varies significantly. The modern legal studies of digitalization are often haphazard and superficial. Lawyers are clearly lagging behind modern trends, which can create a number of serious problems in terms of the legal regulation and loss of humanitarian and legal values accumulated by humanity. This situation really creates a number of serious threats to the legal regulation, because technologies are developing, the number of rules associated with their use is increasing, and these rules are written by the experts in the field of digital economy and IT-technologies. The purpose of the study: to summarize the main theoretical and legal problems arising from the widespread introduction of digital technologies in the legal regulation and legal activity. Research objectives: to define the concept of digitalization; to consider the main trends of scientific research on issues related to the largescale spread of digitalization and artificial intelligence technologies; to identify and formulate the main problems of doctrinal and theoretical plan discussed by the legal community in the context of digitalization; to determine the limits of the real impact of new technologies on the social regulation. Methods: the system, structural and functional ones, the methods of analysis and synthesis, expert evaluation. Results: the paper systematizes the main problems of digitalization that concern modern lawyers. The problems of digitalization are divided into general social ones, concerning threats to the development of society as a whole, and special legal ones, concerning the actual change of the legal regulation and law in the era of digitalization. Conclusions: it is not technologies that need the legal regulation, but the relations with the use of technologies do. As for the "horror stories" about AI and total digitalization, most of the problems lie in the sphere of natural intelligence, not artificial one, in the sense that it is necessary to regulate the actions of natural intelligence carriers in the design of artificial intelligence.

Key words: digitalization, artificial intelligence, digitalization of law, legal regulation, free will, social regulation, essence of law, law.

Citation. Gaivoronskaya Ya.V., Miroshnichenko O.I. Legal Problems of Digitalization: Theoretical and Legal 亏े Aspects. Legal Concept, 2019, vol. 18, no. 4, pp. 27-34. (in Russian). DOI: https://doi.org/10.15688/lc.jvolsu.2019.4.3

Дата поступления статьи: 06.09.2019

ББК 67.0 Дата принятия статьи: 02.10.2019

\section{ПРАВОВЫЕ ПРОБЛЕМЫ ЦИФРОВИЗАЦИИ: ТЕОРЕТИКО-ПРАВОВОЙ АСПЕКТ ${ }^{1}$}

\author{
Яна Владимировна Гайворонская \\ Дальневосточный федеральный университет, г. Владивосток, Российская Федерация \\ Ольга Игоревна Мирошниченко \\ Дальневосточный федеральный университет, г. Владивосток, Российская Федерация
}

Введение: цифровизация - междисциплинарная проблема, но степень ее опосредования специалистами разных сфер существенно разнится. Современные юридические исследования цифровизации часто гре- 
шат бессистемностью и поверхностностью. Юристы явно отстают от современных трендов, что может создать ряд серьезных проблем в плане правового регулирования и утраты накопленных человечеством гуманитарных и правовых ценностей. Такая ситуация действительно создает ряд серьезных угроз правовому регулированию, ведь технологии развиваются, количество правил, связанных с их использованием, увеличивается, а написаны эти правила специалистами в сфере цифровой экономики и IT-технологий. Цель исследования: обобщить основные теоретико-правовые проблемы, возникающие при широком внедрении цифровых технологий в правовое регулирование и юридическую деятельность. Задачи исследования: определить понятие цифровизации; рассмотреть основные тенденции научных исследований по вопросам, связанным с масштабным распространением цифровизации и технологий искусственного интеллекта; выявить и сформулировать основные проблемы доктринального и теоретического плана, обсуждаемые юридической общественностью в контексте цифровизации; определить пределы реального влияния новых технологий на социальное регулирование. Методы: системный, структурно-функциональный, методы анализа и синтеза, экспертной оценки. Результаты: в статье систематизированы основные проблемы цифровизации, волнующие современных юристов. Проблемы цифровизации разделяются на общесоциальные, касающиеся угроз развития общества в целом, и специально-юридические, касающиеся собственно изменения правового регулирования и права в эпоху цифровизации. Выводы: в правовом регулировании нуждаются не технологии, а отношения с использованием технологий. А что касается «страшилок» про ИИ и тотальную цифровизацию, то большая часть проблем лежит в сфере естественного интеллекта, а не искусственного. В том смысле, что регулировать надо действия носителей естественного интеллекта при проектировании интеллекта искусственного.

Ключевые слова: цифровизация, искусственный интеллект, диджитализация права, правовое регулирование, свобода воли, социальное регулирование, сущность права, право.

Цитирование. Гайворонская Я. В., Мирошниченко О. И. Правовые проблемы цифровизации: теоретико-правовой аспект // Legal Concept = Правовая парадигма. - 2019. - T. 18, № 4. - C. 27-34. - DOI: https:// doi.org/10.15688/lc.jvolsu.2019.4.3

\section{Введение}

Цифровизация - междисциплинарная проблема, но степень ее опосредования специалистами разных сфер существенно разнится. Современные юридические исследования цифровизации часто грешат бессистемностью и поверхностностью. Правила игры в современном технологичном мире устанавливают не юристы, юристы вынуждены приспосабливаться к экономическим законам. С одной стороны, это естественно, с другой - имеет место существенное отставание юридических исследований от уровня развития технологий, что не позволяет юристам влиять на происходящие процессы. Значительное количество дискуссионных вопросов современности (например, о принципиальном изменении права или его вытеснении другими регуляторами, о роботизированном правотворчестве и правосудии) ставится не юристами, а аргументация демонстрирует отсутствие специальных правовых знаний и весьма схематичные, на уровне бытового правосознания, представления о правовом регулировании. Такая ситуация действительно создает ряд серьезных угроз правовому регулированию, ведь технологии развиваются, количество правил, связанных с их использованием, увеличивается, а написаны эти правила специалистами в сфере цифровой экономики и IT-технологий.

\section{О понятии цифровизации}

Изначально цифровизация приходит из сферы цифровой экономики как средство повышения эффективности производства и экономики в целом за счет преобразования информации в цифровую форму. Да и сейчас основные потребители цифровизации - это крупный бизнес и наукоемкое производство. Цифровизация пришла на смену автоматизации, компьютеризации, информатизации, позволяя решать несоизмеримо более сложные задачи и в больших масштабах.

Специалисты выделяют цифровизацию в широком и в узком смысле. В узком смысле цифровизация означает перевод информации в цифровую форму. Цифровизация в широком смысле - это современный общемировой тренд развития экономики и общества, который основан на преобразовании в цифровую форму и 
приводит к повышению эффективности экономики и улучшению качества жизни [6, с. 47].

По нашему мнению, применительно к гуманитарным исследованиям на сегодняшний день можно выделить три значения, в которых используется термин «цифровизация»:

- переход с аналоговой формы передачи информации на цифровую;

- «оцифровывание информации», перевод информации в цифровой формат для последующего хранения, распространения и использования;

- широкий комплекс экономических, управленческих, социальных процессов, связанных с использованием и широким распространением собственно цифровых, компьютерных, информационных, электронных и сетевых (телекоммуникационных) технологий, систем искусственного интеллекта в современной жизни.

Когда говорят об угрозах и рисках цифровизации, а также о вызываемых ею социальных проблемах, имеют в виду цифровизацию в широком смысле, в последнем из приведенных контекстов.

\section{Право и цифровизация}

Сама идея статьи родилась на VI Mocковском юридическом форуме (4-6 апреля 2019 г.), при прослушивании докладов участников некоторых секций [7]. В принципе, обзор тематики выступлений форума дает, по нашему мнению, неплохое представление об основных проблемах, выделяемых юристами при анализе вопросов влияния цифровизации и искусственного интеллекта на развитие правовой материи. Кроме этого, этот обзор во многом совпадает с тематикой научных публикаций последних лет по интересующему нас вопросу.

Оценивая направленность юридических исследований в сфере цифровизации и распространения искусственного интеллекта, можно выделить две противоположные тенденции. Во-первых, это попытка отреагировать имеющимися правовыми средствами на широкое распространение отдельных технологий, то есть урегулировать уже формирующиеся / сформировавшиеся экономические отношения или технические новинки. Эта тенденция характерна как для частно-правовых $[4$, с. $23-$
31], так и для публично-правовых [1,78-88], и для комплексных междисциплинарных [3, c. 89-95] исследований по цифровизации. Вовторых, это прогнозирование рисков и проблем цифровизации применительно к обществу развитых технологий будущего. Такие исследования имеют общий, теоретико-правовой или междисциплинарный характер и часто напоминают научную фантастику. Именно в работах такого плана рассуждают о правосубъектности, правах и свободах роботов, необходимости альтернативных регуляторов для отношений людей и не-людей, вытеснении людей роботами с рынка труда и об искусственном погружении большей части населения в виртуальный гейминг, заменяющий людям будущего социальную жизнь.

В рамках данной работы мы хотим дать обзор исследованиям такого рода, выделить основные группы проблем цифровизации в части ее взаимодействия с правом и социальным регулированием.

Итак, проблемное поле цифровизации через призму юридической профессии выглядит следующим образом. Прежде всего, все проблемы, волнующие юристов в связи с цифровизацией юридической деятельности и правового регулирования, распространением систем искусственного интеллекта, по тематике и сфере исследуемых отношений можно разделить на две группы: общесоциальные и специально-юридические проблемы. «Цифровые технологии» в данном случае - достаточно условный обобщающий термин, произнося который, мы предполагаем использование в правовом регулировании компьютерных, информационных, сетевых, электронных, телекоммуникационных технологий, систем искусственного интеллекта, информации в цифровой форме и т. д.

К «специально-юридическим» (внутриправовым) проблемам относятся:

- проблема свободы воли;

- проблема исключенности юристов из сферы формирования нового порядка;

- проблема социальности правового регулирования;

- проблема формирования альтернативных регуляторов.

Общесоциальные проблемы цифровизации, в свою очередь, можно разделить на со- 
циальные и экономические. К социальным угрозам цифровизации относятся: безработица; принципиальное изменение рынка труда и социальной архитектуры в целом; выраженное и стремительное расслоение общества (экономическое, интеллектуальное, в перспективе - физическое, генетическое, что связано с доступностью новейших медицинских технологий обеспеченным слоям населения); деградация человечества (связанная со снижением стимулов к саморазвитию в условиях обеспечения основных физических потребностей и комфорта за счет автоматизации труда и быта, а также порожденная снижением качества образования и потерей необходимости в активном интеллектуальном развитии); исключенность из социального контекста (за счет потери имеющихся социальных институтов, связанных с необходимостью обязательного труда); потеря смысла в высшем и/ или профессиональном образовании. Социальные проблемы плавно переходят в комплекс биоэтических проблем, которые в целом тоже имеют социальный характер. Здесь можно указать на следующие вопросы / угрозы. Во-первых, юристов и философов интересует вопрос о том, кто является носителем прав человека. Распространимы ли они на цифровые сущности? Во-вторых, сетевое общество, информационное общество - это абсолютно контролируемое общество, общество несвободы, что является естественным результатом развития технологий сбора и обработки информации. Высокотехнологичная версия крепостного права, по словам одного из докладчиков Московского юридического форума. «Программируемое общество» - термин В.В. Лазарева, предлагаемый взамен используемых сейчас «постиндустриальное общество», «информационное общество». В-третьих, прогнозируемой реальностью тотальной цифровизации (включая развитие искусственного интеллекта) становится массовая «паразитация» человечества, утрата человеческой природы.

Экономические проблемы связаны с футуристическими прогнозами принципиального изменения экономических отношений в результате всеобъемлющей цифровизации и, как следствие, изменения социального строя. Например, в соответствии с одним из прогно- зов, богатый человек будущего - это просто человек, имеющий работу. Другой прогноз прочит «программируемому обществу» возврат к советской модели экономики, одной из задач которой было предоставлять людям занятость, а не обеспечивать экономическую эффективность производственных процессов.

Остановимся подробнее на некоторых специально-юридических проблемах цифровизации.

Проблема свободы воли объединяет в себе следующие вопросы, волнующие юристов в связи с цифровизацией юридической деятельности и правового регулирования, распространением систем искусственного интеллекта:

- правосубъектность цифровых сущностей;

- свобода выбора поведения: подмена свободной воли субъекта права волей оператора (программиста, создателя оболочки, матрицы выбора);

- вопросы ответственности (можно ли говорить о юридической / иной ответственности сущности, не обладающей свободой воли?);

- природа человека, сущность человека, критерий различения субъекта и объекта в праве.

Свобода воли, возможность выбора варианта поведения относятся, с точки зрения ряда концепций правопонимания, к сущностным характеристикам права. По мнению А.А. Иванова, заведующего кафедрой гражданского и предпринимательского права НИУ «Высшая школа экономики», «...полная машинизация права невозможна до тех пор, пока сохраняется человеческое общество, в котором люди наделены свободой воли и могут действовать нелогично или против правил», «призывать к машинизации права - значит требовать уничтожения этого общества и перехода к цивилизации машин». Свободная воля человека, как пишет А.А. Иванов, является той главной внутренней причиной, которая препятствует машинизации права. «Жизнь многогранна и постоянно взламывает стабильные нормы, которые перестают соответствовать потребностям людей. А люди, в свою очередь, начинают их обходить, искать новые пути удовлетворения своих интересов. <..> ...порой девиантное (отклоня- 
ющееся) поведение полезно обществу и соответствует природе человека. А машинизировать такое поведение принципиально нельзя» [2]. С этими рассуждениями хочется согласиться.

Специально-юридические проблемы цифровизации взаимосвязаны. Проблемы свободы воли, альтернативных социальных регуляторов, социального характера права переплетаются, их обособление нами в качестве самостоятельной тематики достаточно условно. Например, проблема социальности правового регулирования включает в себя следующие вопросы, требующие мировоззренческого и теоретико-правового анализа:

- Что есть человек?

- Что есть социум?

- Кто есть субъект и что есть объект правового регулирования?

Изначально право - социальное по своей природе явление, что предполагает, что оно регулирует отношения между людьми. Потенциально возможное распространение сильного искусственного интеллекта заставляет ученых заново пересмотреть это признак и определиться с ответом на вопрос: отношения меду кем и кем будет регулировать право будущего? Например, одним из прогнозов является противопоставление права людей и права вещей, а также сужение сферы правового регулирования: регулирование правом отношений типа «Человек - Человек» и регулирование НЕ-правом отношений типа «Человек - Нечеловек» и «Нечеловек - Нечеловек».

С проблемой социальности права связана и проблема альтернативных регуляторов в цифровом обществе. Футурологические изыскания на правовом поле подводят к выводу о том, что в будущем право будет не универсальным, не доминирующим и отнюдь не самым перспективным правовым регулятором. А вот детали этого прогноза сумбурны. Чаще всего можно слышать о противопоставлении права и программного кода и о вытеснении права последним. Кроме этого, альтернативой универсальности правового регулирования может стать уже упомянутое нами разделение на право людей и право вещей. Надо полагать, с разными правовыми режимами. Еще одной прогнозируемой альтернативой является замена правового регу- лировании (в привычном юристам современном понимании) программированием социальной реальности.

Представляется, что одной из проблем таких прогнозов является непонимание специфики предмета, нехватка специальных знаний: инженерам - о праве, юристам - о технологиях. Например, если рассматривать программный код просто как средство фиксации и трансляции информации в специфической форме, то непонятно, что принципиально изменится от того, каким способом (в какой форме, на каком языке и в какой системе символов) мы будем фиксировать одни и те же правила поведения? Но если под программным кодом иметь в виду алгоритмы, выбираемые искусственным интеллектом при принятии решений, то проблема выглядит совсем по-другому. Сергей Никитин, менеджер по продукту «Газинформсервис», считает наиболее актуальным в плане информационной безопасности вопрос доверия к разработчикам аналитических систем, в том числе на основе ИИ. «ИИ предназначен для помощи в принятии решений на основании обработки больших объемов данных, но мы не всегда знаем, какие алгоритмы в него заложены создателями, насколько они корректны, - сказал С. Никитин в своем выступлении на V Digital City Forum РБК. - А ведь от этого зависит результат, который выдаст система» (цит. по: [1]).

Моделирование правовой реальности опасная тенденция, при которой воля общества, индивида и социальные закономерности заменяются волей разработчика программы, волей создателя цифрового кода. Перевод правовой материи в алгоритмы поведения машин осуществляют не юристы, поэтому итоговый функционал программной оболочки будет существенно отличаться от первоначального «духа закона», причем в сторону упрощения и обеднения вариантов. На программу нельзя пожаловаться, высказать претензии. Это лишает человека свободы воли и выбора, человек остается в рамках выборов, заложенных волей создателей оболочки. Такая ситуация гипертрофирует субъективный фактор в социальном регулировании и заменяет социальное регулирование (в современном научном понимании) программированием, механистическим моделированием реально- 
сти. К социальной реальности начинают применяться технологии гейминга, моделирования игровой реальности, где функционал субъектов (игроков) четко определен и весьма ограничен по сравнению с многогранностью человеческой природы. Свобода воли подменяется ролевым функционалом.

Требования к цифровому праву и инновационному правовому регулированию вообще вырабатываются не юристами и часто без юристов. В этих условиях очень легко выплеснуть с водой и младенца: многовековой ценностно-регулятивный багаж юриспруденции может оказаться отброшенным просто в угоду очарованию прогресса, а также потому, что определяют контуры регулирования люди с обыденным правосознанием, специалистытехники, склонные уравнивать регулирование поведения и программные алгоритмы и игнорировать этический, аксиологический и социокультурный подтекст права.

Еще одной проблемой юридической футурологии в контексте цифровизации является, как нам кажется, увлечение новизной и прогрессивностью цифровизации как явления. Это заставляет искать и видеть принципиальные изменения там, где их нет. Для примера приведем еще один вариант альтернативных регуляторов будущего. В докладе Т.Я. Хабриевой, директора Института законодательства и сравнительного правоведения при Правительстве РФ, на VI Московском юридическом форуме [7] в качестве одного из вариантов была представлена разработка института, названная модульным регулированием. Модуль включает в себя следующие элементы:

- международно-правовые стандарты;

- законы и подзаконные акты;

- акты толкования международных стандартов и национального законодательства;

- акты технического регулирования;

- иные социальные регуляторы (этика, обычаи, корпоративные нормы).

Сама идея комплексного модульного регулирования в условиях конвергенции технологий логична и перспективна. Но состав модуля вызывает сомнения, он сформирован механистически, на базе неочевидного критерия. Во-первых, такое искусственное объединения сущностно-разных элементов в одно целое противоречит научной методологии. Во- вторых, сами элементы модуля чего-то принципиально нового в теорию регуляции не привносят, все перечисленное охватывается уже известными категориями системы нормативного регулирования, элементом которой, в свою очередь, является право, выражающееся в различных источниках. Иными словами, заявляемая новизна модульного регулирования для условий технологической революции выглядит невнятно.

Выше мы говорили о двух тенденциях изучения проблем цифровизации на современном этапе: отраслевое исследование отдельных технологий с предложениями по точечному реформированию имеющегося законодательства, с одной стороны, и философскоумозрительное, этико-ориентированное прогнозирование рисков и угроз изменения регулятивного контекста под влиянием цифровизации - с другой. В этих двух крайностях не хватает середины: концептуальной, комплексной теоретико-правовой разработки моделей правового регулирования и правотворчества для высокотехнологичного общества. Нет ничего более практичного, чем хорошая теория. Право высоких технологий надо не только понимать как правоприменительную деятельность, но и рассматривать его с концептуальных и доктринальных позиций.

Цифровизация - междисциплинарная проблема, и прогностическое изучение ее, в том числе с точки зрения угроз в отдаленной перспективе, необходимо. Однако пока теоретики права и отраслевики с воодушевлением обсуждают проблемы потенциальной правосубъектности роботов (что само по себе дело нужное), в мире параллельно формируется правовое регулирование, техническое регулирование, которое создается неюристами, спорадически и без концептуальной разработки.

\section{Выводы}

Очевидно, задачей на перспективу для ученых-юристов является создание превентивного правового регулирования, не допускающего распространения цифровых технологий и автоматизации в сферы, где решаются судьбы людей. Ближайшими задачами являются исследования рисков широкого распространения цифровых технологий в разных сферах 
общественной жизни. «Можно ли это автоматизировать?» и «Нужно ли это автоматизировать?» - два разных вопроса, ответы на которые могут помочь найти баланс между технологическим прогрессом и социальной стабильностью. Аналогичные вопросы нужно задать себе и по отношению к цифровизации.

Правы те, кто говорит, что не надо регулировать прогресс. В правовом регулировании нуждаются не технологии, а отношения с использованием технологий. А что касается страшилок про ИИ и тотальную цифровизацию, то большая часть проблем лежит в сфере естественного интеллекта, а не искусственного. В том смысле, что регулировать надо действия носителей естественного интеллекта при проектировании интеллекта искусственного. А при таком взгляде на вопрос право остается востребованным регулятором с высоким регулятивным потенциалом, а необходимость неких принципиально иных регуляторов поведения оказывается спорной.

\section{ПРИМЕЧАНИЕ}

${ }^{1}$ Исследование выполнено при финансовой поддержке РФФИ в рамках научного проекта № 1829-16129.

The research was funded by RFBR, research project No. 18-29-16129.

\section{СПИСОК ЛИТЕРАТУРЫ}

1. Журавлева, А. Опасности цифровизации или цифровизация в опасности : [Обзор круглого стола в рамках V Digital City Forum РБК (Материалы подготовлены редакцией партнерских проектов РБК + )] / А. Журавлева // Digital Forum РБК. Вып. № 5, 25 июня [2019 г.]. - Электрон. дан. - Режим доступа: https://spb.plus.rbc.ru/news/ 5cb448c57a8aa90a3814c68e. - Загл. с экрана.

2. Иванов, А. А. О глубине машинизации права / А. А. Иванов // Закон. - 2018. - № 5. - С. 35-41. Электрон. текстовые дан. - Доступ из справ.-правовой сист. «КонсультантПлюс» (дата обращения: 11.07.2019).

3. Информационная безопасность России в цифровой экономике: экономические и правовые аспекты / Е. Е. Фролова, Т. А. Полякова, М. Н. Дудин, Е. П. Русакова, П. А. Кучеренко // Journal of advanced research in law and economics. - 2018. T. 9, № 1. - C. 89-95.
4. Иншакова, А. О. Цифровые технологии альтернативных методов разрешения споров: зарубежная практика и перспективы применения в России / А. О. Иншакова, Ю. А. Тымчук // Право и управление. XXI век. -2018. - № 1 (46). - С. 23-31.

5. Снижение киберрисков в сфере электронных платежей: организационно-правовые меры / М. Н. Дудин, В. Н. Заско, Е. Е. Фролова, Н. Г. Павлова, Е. П. Русакова // Journal of advanced research in law and economics. - 2018. - T. 9, № 1. - C. 78-88.

6. Халин, В. Г. Цифровизация и ее влияние на российскую экономику и общество: преимущества, вызовы, угрозы и риски / В. Г. Халин, Г. В. Чернова // Управленческое консультирование. - 2018. № $10 .-$ C. $46-63$.

7. XVI Международная научно-практическая конференция «Российская правовая система в условиях четвертой промышленной революции» (Кутафинские чтения) : материалы конференции. Ч. 1 / ред. совет: В. Н. Синюков, А. В. Корнев, С. В. Липень, С. М. Зубарева [и др.]. - М. : Проспект, 2019. -408 с.

\section{REFERENCES}

1. Zhuravleva A. Opasnosti tsifrovizatsii ili tsifrovizatsiya v opasnosti. Obzor kruglogo stola v ramkax V Digital City Forum RBK [The Dangers of Digitalization or Digitization is in Danger. Overview of the Round Table in the Framework of the V Digital City Forum RBC] (Materials prepared by the editorial staff of the partner projects, RBC+). Digital Forum RBC, Iss. 5, June 25, 2019. URL: https://spb.plus.rbc.ru/ news/5cb448c57a8aa90a3814c68e.

2. Ivanov A. A. O glubine mashinizatsii prava [On the Depth of Mechanization of Law]. Zakon [Law], 2018. no. 5, pp. 35-41. Access from Reference Legal System "KonsultantPlyus" (accessed 11 July 2019).

3. Frolova E.E., Polyakova T.A., Dudin M.N., Rusakova E.P., Kucherenko P.A. Informatsionnaya bezopasnosnost Rossii v tsifrovoy economike: economicheskiye i pravovye aspekty [Information Security of Russia in the Digital Economy: The Economic and Legal Aspects]. Journal of advanced research in law and economics, 2018, vol. 9, no. 1, pp. 89-95.

4. Inshakova A.O., Tymchuk Yu.A. Tsyfrovye tekhnologii alternativnykh metodov razresheniya sporov: zarubezhnaya praktika i perspectivy primeneniya v Rossii [Digital Technology Alternative Dispute Resolution: Foreign Practice and Prospects of Application in Russia]. Pravo i upravleniye [Law and Management. TwentyFirst Century], 2018, no. 1 (46), pp. 23-31.

5. Dudin M.N., Zasko V.N., Frolova E.E., Pavlova N.G., Rusakova E.P. Snizhenie kiberriskov v sfere elektronnykh platezhey: organizatsionno- 


\section{ГЛАВНАЯ ТЕМА НОМЕРА}

pravovye mery [Mitigation of Cyber Risks in the Field of Electronic Payments: Organizational and Legal Measures]. Journal of advanced research in law and economics, 2018, vol. 9, no. 1, pp. 78-88.

6. Khalin V. G., Chernova G. V. Tsifrovizatsiya i ee vliyaniye na rossiyskuyu ekonomiku i obshchestvo: preimushchestva, vyzovy, ugrozy i riski [Digitalization and Its Impact on Russian Economy and Society: Advantages, Challenges, Threats and Risks]. Upravlencheskoe konsultirovanie [Management Consulting], 2018, no. 10, pp. 46-63.
7. Sinyukov V.N., Kornev A.V., Lipen S.V., Zubareva S.M. et al., eds. XVI Mezhdunarodnaya nauchno-prakticheskaya konferentsiya «Rossiyskaya pravovaya sistema v usloviyakh chetvertoy promyshlennoy revolyutsii» (Kutafinskie chteniya): materialy konferentsii. Ch. 1 [16 ${ }^{\text {th }}$ International Scientific and Practical Conference "Russian Legal System in the Conditions of the Fourth Industrial Revolution" (Kutafin Readings). Conference Proceedings. Part 1]. Moscow, Prospect Publ., 2019. $408 \mathrm{p}$.

\section{Information about the authors}

Yana V. Gaivoronskaya, Candidate of Sciences (Jurisprudence), Associate Professor, Department of Theory and History of State and Law, Far Eastern Federal University, Ajax, 10, 690065 Vladivostok, Russian Federation, yanavl@yandex.ru, https://orcid.org/0000-0002-7606-4444

Olga I. Miroshnichenko, Candidate of Sciences (Jurisprudence), LL.M, Associate Professor, Department of Theory and History of State and Law, Far Eastern Federal University, Ajax, 10, 690065 Vladivostok, Russian Federation, olga-star.05@mail.ru, https://orcid.org/0000-0002-8248-6782

\section{Информация об авторах}

Яна Владимировна Гайворонская, кандидат юридических наук, доцент кафедры теории и истории государства и права, Дальневосточный федеральный университет, пос. Аякс, 10, 690065 г. Владивосток, Российская Федерация, уanavl@yandex.ru, https://orcid.org/0000-0002-7606-4444

Ольга Игоревна Мирошниченко, кандидат юридических наук, LL.M, доцент кафедры теории и истории государства и права, Дальневосточный федеральный университет, пос. Аякс, 10, 690065 г. Владивосток, Российская Федерация, olga-star.05@mail.ru, https://orcid.org/0000-0002-8248-6782 